\title{
Investigation of heat transfer and fluid flow in activating TIG welding by numerical modeling
}

\author{
Xinxin Wang ${ }^{\mathrm{a}, \mathrm{b}}$, Jiankang Huang ${ }^{\mathrm{b} *}$, Yong Huang ${ }^{\mathrm{b}}$, Ding Fan ${ }^{\mathrm{b}}$, Yanning Guo ${ }^{\mathrm{b}}$ \\ ${ }^{a}$ College of Materials Science and Engineering, Chongqing University of Technology, 400054, \\ Chongqing, China \\ ${ }^{\mathrm{b}}$ State Key Laboratory of Advanced Processing and Recycling of Non-ferrous Metals, 730050, \\ Lanzhou, China \\ *Correspondent: sr2810@163.com (Jiankang Huang)
}

\begin{abstract}
Heat transfer and fluid flow of arc plasma and weld pool in tungsten inert gas (TIG) welding and activated flux tungsten inert gas (A-TIG) welding of SUS 304 stainless steel are investigated comparatively though a 3D unified model. The model differs from the previous ones in that it considers the arc length more realistic for welding production. Tungsten electrode, anode (work piece) and arc plasma are all included. The effects of buoyance, plasma drag force, Lorentz force and Marangoni force on the weld pool flow are taken into account. By solving the conservation equations of mass, momentum, energy as well as Maxwell equations, the distributions of temperature and velocity of arc plasma and weld pool are obtained for TIG and A-TIG welding. The heat flux, current density and shear stress at the
\end{abstract}


weld pool are presented. Dimensionless numbers are employed to compare the relative importance of the driven forces and that of convection and conduction in heat transfer of the weld pool. It is demonstrated that there is no significant difference in the heat flux at the weld pool, and total heat input to the anode and thermal efficiency is almost equal for TIG and A-TIG welding. The current density and the heat flux at the weld pool are more concentrated in more realistic welding condition. As a result, both of the temperature of the weld pool for TIG welding and A-TIG welding increases, while the latter is more significant. Marangoni force ranges from zero to $100 \mathrm{~Pa}$ and dominant the weld pool flow. Compared with the conventional TIG welding, the reversion of the Marangoni force results in inward flow and thus causes inward heat convection in weld pool of A-TIG welding. Heat convection was the main mechanism of heat transfer for SUS 304 stainless steel, which results in directly both shallow weld pool shape in TIG welding and remarkably increased weld pool depth and slightly constricted weld pool width in A-TIG welding.

\section{Key words}

Heat transfer, Fluid flow, A-TIG, Convection

\section{Introduction}

Activated flux TIG welding, referred to as A-TIG, is a high efficiency welding process due to its remarkable improvement in weld penetration and thus its productivity. Since it comes to the world in E. O. Paton Electrical Welding Institute in 1960s [1], the methode has been studied through many experiments for several decades [2-11]. For iron alloys, it can be found [6-11] that the minor activating elements such as oxygen, sulphur, selenium and so on can results in a significant increase of weld depth. Inspired by these phenomena, Fan et al [12] 
proposed a new A-TIG welding process and named it Arc assisted Activating TIG (AA-TIG) welding for its further application and automation. It is assumed that the improved weld penetration caused by the inward flow induced by the fact that activating element reverses the temperature dependence of surface tension of the weld pool. However, only several literatures observed directly the flow pattern change of the weld pool by experiment in A-TIG welding [13-14], since the complexity associated with welding process makes the direct observation beyond the present visualization technology. Fortunately, numerical simulation gives us a useful way to reproduce the details and undiscovered physical mechanisms in welding process qualitatively and quantitatively.

Many researchers devoted to modeling the heat transfer and fluid flow in arc plasma [15-17] or those in molten pool of welding process [14, 18-20] individually. In these models, more or less assumptions were employed inevitably at the boundaries, such as cathode and/or anode surfaces for the both models. For the assumptions are based on the experiments in specified conditions, they are suitable for these conditions and may cause deviations in other case. As the arc and weld pool are an integrated system, more and more researchers began to give insight into developing unified models, where the interaction of the arc plasma and the electrodes were taken into account, so that the models more approach to actual process. Choo et al [21, 22] initially studied the weld pool behavior by calculating arc plasma and its heat and electrical fluxes transferred to the weld pool, though the welding arc and weld pool were calculated separately. By using the similar treatment, Dong et al [23] examined the weld pool convections with the effect of the active element of oxygen based on solving the model of helium arc. Further, Tanaka et al [24] developed a 2D unified model to include the arc plasma, 
tungsten electrodes and weld pool. They investigated the energy balance between the arc plasma and the weld pool and also the effects of the various driven forces on the weld pool formation for TIG welding. Moreover, the effect of sulphur on the weld pool formation was investigated by Tanaka [25] based on the model developed in literature [24]. Lowke et al [26] studied the effect of activating flux of titanium dioxide on the arc plasma and the highlighted the interaction of the arc plasma and weld pool for A-TIG welding through their integrated numerical model. It is suggested that the increased weld penetration was induced by the insulating effect of the titanium dioxide on the arc current. In recent years, it is noted that that the effect of metal vapor on the arc plasma and weld pool of the TIG welding was considered by Mougenot et al [27] and Tanaka et al [28] in recent years. Nevertheless, these studies focused more on the arc plasma characteristics and less on the weld pool. The detailed heat flux and momentum transfer to the weld pool, heat transfer and fluid flow in the weld pool for TIG and A-TIG welding, to some extent, in need of essential investigation. On the other hand, arc length was set as $5 \mathrm{~mm}$ or more in these studies, this parameter is relatively rare used compared to $2 \sim 3 \mathrm{~mm}$ gap in realistic welding production. Unfortunately, there has seldom reports concerning this short arc length for A-TIG welding yet. In addition, the 2D model developed by these studies is suitable to the case of rotational symmetry only.

In this paper, we investigated the arc plasma and the weld pool for TIG welding and AA-TIG welding of SUS304 stainless steel. Welding conditions more close to the realistic welding is chosen as parameters in this model. A 3D mathematical model similar to that developed in prior study [29] is used to investigate the arc plasma and weld pool. Since the welding process is one kind of A-TIG welding, we call it A-TIG welding for convenience in 
the following. The temperature and flow velocity of the arc plasma and weld pool are presented firstly. The heat flux, current density and shear stress at the weld pool for both TIG and A-TIG welding are examined as well. Dimensionless numbers are employed to compared the relatively importance of the driven forces and that of heat convection and heat conduction in the weld pool. As a result, the detailed information for the weld pool are presented and mechanisms of the weld pool formation in TIG welding and A-TIG welding of SUS304 stainless steel are clarified.

\section{Mathematical models}

In present model, the general assumptions accepted by many studies are employed: the arc plasma is in local thermal dynamic (LTE), that means the temperatures of the electron and heavy particles are equal[15-17, 21-28], this assumption is always accurate enough for high current; the arc plasma is optically thin and the radiation can be modeled by a radiation loss per unit volume [15-17, 21-28]; the arc is free burning in pure argon atmosphere and welding process is stationary; the heat dissipation due to viscosity effects and the gravity is neglected in the arc plasma; the free surface of the weld pool is flat since the weld pool surface depression can neglected provided the current is lower than $200 \mathrm{~A}[15-17,21-28]$. The metal vapor is neglected for the reason that its effect on the arc plasma and thus on the weld pool is not considerable for argon arc, according to the study in [27], [28] and [30]; anode material is treated as porous media and the enthalpy-porosity technique [31] is employed to formulate the phase change, i.e. the weld pool formation.

Conservations equations including continuity equation, momentum conservation equation, energy conservation equation, current continuity equation and potential equation of magnetic 
vector are solved through general formulate as follows:

$$
\frac{\partial(\rho \varphi)}{\partial t}+\nabla \cdot(\rho \boldsymbol{v} \varphi)=\nabla \cdot(\Gamma \nabla \varphi)+S_{\varphi}
$$

where $\rho$ is mass density, $t$ is time, $\varphi$ represents general variable, $v$ is velocity, $\Gamma$ represents general diffusion coefficient and $S_{\varphi}$ means general source term. Provided the $\varphi$ and $\Gamma$ are given corresponding coefficients and source terms, respectively, we can obtain the conservation equations for mass, momentum and energy, respectively. Regarding the electromagnetic fields, electrical potential $\Phi$ and magnetic vector potential $\boldsymbol{A}$ are adopted to formulate it and both of them satisfy the equation (1) as well. The $\varphi, \Gamma$ and $S_{\varphi}$ given for each conservation equation are listed in table 1. It is noted that for the steady state problem, the first term on the left side of (1), which represents the variation of $\varphi$ with the time, equals zero. This corresponds to the arc plasma model in present study.

Table 1 Conservation equations in generalized form

\begin{tabular}{llll}
\hline Equations & $\varphi$ & $\Gamma$ & $S_{\varphi}$ \\
\hline (2) Mass & 1 & 0 & 0 \\
(3) $x$ Momentum & $v_{x}$ & $\mu$ & $-\frac{\partial P}{\partial x}+\frac{1}{3} \frac{\partial}{\partial x}(\mu \nabla \cdot v)+j_{y} B_{z}-j_{z} B_{y}$ \\
(4) $y$ Momentum & $v_{y}$ & $\mu$ & $-\frac{\partial P}{\partial y}+\frac{1}{3} \frac{\partial}{\partial y}(\mu \nabla \cdot v)+j_{z} B_{x}-j_{x} B_{z}$ \\
(5) $z$ Momentum & $v_{z}$ & $\mu$ & $-\frac{\partial P}{\partial z}+\frac{1}{3} \frac{\partial}{\partial z}(\mu \nabla \cdot v)+j_{x} B_{y}-j_{y} B_{x}+\rho g$ \\
(6) Energy & $T$ & $k$ & $\frac{j^{2}}{\sigma_{\mathrm{e}}}+\frac{5 k_{B}}{2 e} \boldsymbol{j} \cdot \nabla T-S_{\mathrm{R}}$ \\
(7) Current & $\Phi$ & $-\sigma_{\mathrm{e}}$ & 0 \\
(8) Potential vector & $\boldsymbol{A}$ & -1 & $-\mu_{0} j$ \\
\hline
\end{tabular}

In above equations, $v_{x}, v_{y}$ and $v_{z}$ are the components of the velocity vector $v$ in $x, y$ and $z$ 
direction, respectively; $\mu$ is dynamic viscosity and $P$ is pressure; $j_{x}, j_{y}$ and $j_{z}$ are the components of the current density vector $j$ in $x, y$ and $z$ direction, respectively, also $B_{x}, B_{y}$ and $B_{z}$ are the components of the magnetic flux $\boldsymbol{B} . \boldsymbol{g}$ is gravity acceleration, $\sigma_{\mathrm{e}}$ is electrical conductivity and $k$ is thermal conductivity; $k_{\mathrm{B}}$ is Boltzmann constant, $e$ is elementary charge and $S_{\mathrm{R}}$ is radiation loss. Current density $\boldsymbol{j}$ is calculated by Ohm's law, i.e. $\boldsymbol{j}=-\sigma_{\mathrm{e}} \nabla \Phi$; magnetic flux is deduced from $\boldsymbol{B}=\nabla \times \boldsymbol{A}$, and the Lorentz force can be obtained by $\boldsymbol{F}=\boldsymbol{j} \times \boldsymbol{B}$ subsequently.

At the interface between the arc plasma and cathode, coupled boundary is employed to treat the electrical and thermal fluxes. At the anode surf ace, the heat flux to the workpiece expressed as

$$
q_{\mathrm{a}}=q_{\mathrm{c}}+q_{\mathrm{e}}+q_{\mathrm{r}}=-k \frac{\partial T}{\partial z}+\left|j_{z}\right| \Phi_{\mathrm{a}}-\varepsilon_{\mathrm{r}} \sigma T^{4}
$$

which means the anodic energy acquired due to heat conduction $q_{\mathrm{c}}$, electron absorption $q_{\mathrm{e}}$ and radiation loss $q_{\mathrm{r}} . \Phi_{\mathrm{a}}$ is work function of the anode material and equals $4.65 \mathrm{~V}$ [24], $\varepsilon_{\mathrm{r}}$ is emissivity and $\sigma$ is Stefan-Boltzmann constant. The momentum across the interface between the arc and the anode consists of plasma drag $\tau_{\mathrm{p}}$ and Marangoni force $\tau_{\mathrm{M}}$, and can be written as

$$
\tau_{i}=\tau_{\mathrm{p}}+\tau_{\mathrm{M}}=-\mu_{\mathrm{p}} \frac{\partial v_{i}}{\partial z}+\frac{\partial \gamma}{\partial T} \frac{\partial T}{\partial i}(i=x, y)
$$

Where $\gamma$ is surface tension of the weld pool, and the temperature dependence of the surface tension for TIG welding is $-0.458 \times 10^{-3} \mathrm{~N} \cdot \mathrm{m}^{-1} \mathrm{~K}^{-1}$ [23], and that for the A-TIG welding is $0.364 \times 10^{-3} \mathrm{~N} \cdot \mathrm{m}^{-1} \mathrm{~K}^{-1}[29]$

Computation domain and boundary is illustrated in figure 1. Area A is gas inflow where we give the velocity distribution to yield argon flow rate of $12 \mathrm{~L} / \mathrm{min}$, and area B is gas out 
flow. Area $\mathrm{C}$ and $\mathrm{D}$ are wall boundaries, and the heat transfer condition with ambient atmosphere is imposed. Area $\mathrm{E}$ is electrodes section, a uniform current density normal to the surface and an isothermal condition of $1800 \mathrm{~K}$ [32] are imposed.

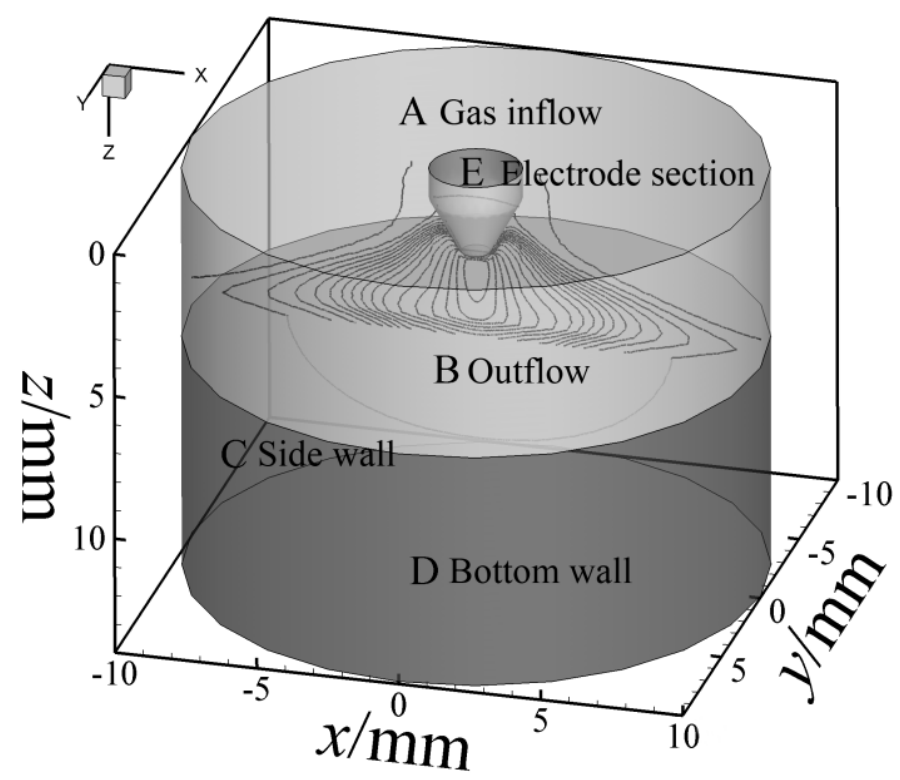

Figure 1. Schematic illustration of the computation domain

\section{Numerical considerations}

Tungsten electrode, arc plasma and work piece are included in a Cartesian coordinates. The computation domain is illustrated in figure 1 . The tungsten electrode diameter is $3.2 \mathrm{~mm}$ with a conical angle of 60 degree and a tip radius of $0.5 \mathrm{~mm}$. Arc length is set as $3 \mathrm{~mm}$ so that it is more close to the practical welding process. The anode diameter is $20 \mathrm{~mm}$ and the thickness is $8 \mathrm{~mm}$. The computation domain is discrete into hexahedral meshes and the local mesh close to the electrode is refined, and the grids adjacent to the anode and cathode are $0.3 \mathrm{~mm}$ and 0.1 $\mathrm{mm}$, respectively, according to the advice of Lowke et al [33]. The thermophysical properties and transport coefficient of the arc plasma are from [21] and those of the anode material are from [27] and [34].

Mathematical models are solved by CFD code FLUENT. The computation domain is divided 
into three subdomains of tungsten electrode, arc plasma and workpiece/anode by interfaces between the arc plasma and the electrodes. A two-side wall with zero thickness is employed as the arc-anode interface to impose the heat flux condition, i.e. (9). The heat flux condition is imposed on weld pool side, while the value condition is imposed on the other. This treatment allows us to model the temperature of anode arc root time dependently in practical welding. Energy equation and electromagnetic equations are solved in the whole domain while the other equations are solved in fluid domain. The conservation equations are solved by SIMPLEC algorithm with second up-wind scheme. During calculation, after the steady state arc plasma was computed to convergence, the solver is switched to unsteady state and the thermal conditions are set at the anode surface to calculate work piece and arc plasma. After the anode melts, the shear stress condition is exerted on weld pool to compute until preset time. The convergence criterion for energy equation is $10^{-6}$, and that for other equations are $10^{-3}$. For the governing equations are nonlinear and highly temperature dependent, relaxation factors are accommodated to ensure convergence.

\section{Results and discussion}

The condition of welding current is $150 \mathrm{~A}$, electrode gap is $3 \mathrm{~mm}$, and welding time is $4 \mathrm{~s}$. This section we present the results for TIG welding and A-TIG welding, respectively, in similar welding conditions. Various heat fluxes and the shear stresses at the anode surface are represented and discussed.

\subsection{Temperature and flow fields}

Calculated temperature and velocity of arc plasma and weld pool for TIG welding are illustrated in figure 2. It can be seen from figure 2 (a) that a well-known "bell-shaped" arc 
shape forms. This shape type can be found in many published photographs of arc plasma. The highest temperature is $17755 \mathrm{~K}$ at the location about $0.5 \mathrm{~mm}$ below the cathode tip. This value is $775 \mathrm{~K}$ higher than the results of Tanaka et al [24], where they measured a peak temperature of $17000 \mathrm{~K} 1 \mathrm{~mm}$ below the cathode tip for 150 A argon arc with a $5 \mathrm{~mm}$ electrode gap. Bachmann et al [35] measured a maximum temperature of $17600 \mathrm{~K}$ for $150 \mathrm{~A}$ argon arc with $8 \mathrm{~mm}$ arc length. As demonstrated experimentally by Haddad and Farmer [36], the shorter arc length can produce somewhat higher temperature. Therefore, it is believed that the temperature predicted by present model is convincing reasonably. Near the electrodes there exist great temperature gradient due to the significant difference of electrical conductivity between the electrodes and the arc plasma. Arc voltage drop is $8.74 \mathrm{~V}$, which lower about several volts than the experimental data. The reason lies in simplification of our model in which the electrode sheaths are excluded and sheaths drop is not computed. That means the arc column voltage drop is calculated only. For the weld pool, its profile is wide and shallow and the maximum temperature is $2323 \mathrm{~K}$, which is just about one hundred Kelvin higher than the predicted value by Tanaka et al [28]. For the $3 \mathrm{~mm}$ arc length, the heat flux can be more concentrated and the temperature tends to increase accordingly. The weld depth is less than 1 $\mathrm{mm}$ and the weld width exceeds $8 \mathrm{~mm}$.

Flow velocity for arc plasma and weld pool are shown in in figure 2(b), it can be seen a classic plasma jet flow from the cathode to the anode is generated due to the strong electromagnetic force, and then flows out along the anode surface due to the obstacle of the anode. This famous cathode jet has been found in plasma processing including welding process. Its maximum velocity reaches $146 \mathrm{~m} / \mathrm{s}$ at the central location of the arc column. The 
flow velocity is in the order of $10^{2} \mathrm{~m} / \mathrm{s}$ and is consistent with the many calculated results [15-18, 21-29] and measured data [37]. For the molten metal flow in the weld pool, an outward recirculation forms and the peak value for this flow reaches $0.13 \mathrm{~m} / \mathrm{s}$ at the half radius of the weld pool surface. This is coincide with the predicted flow velocity of the weld pool by many previous researches [22-29] where the velocities are reported in the order of $10^{-1} \mathrm{~m} / \mathrm{s}$ as well.

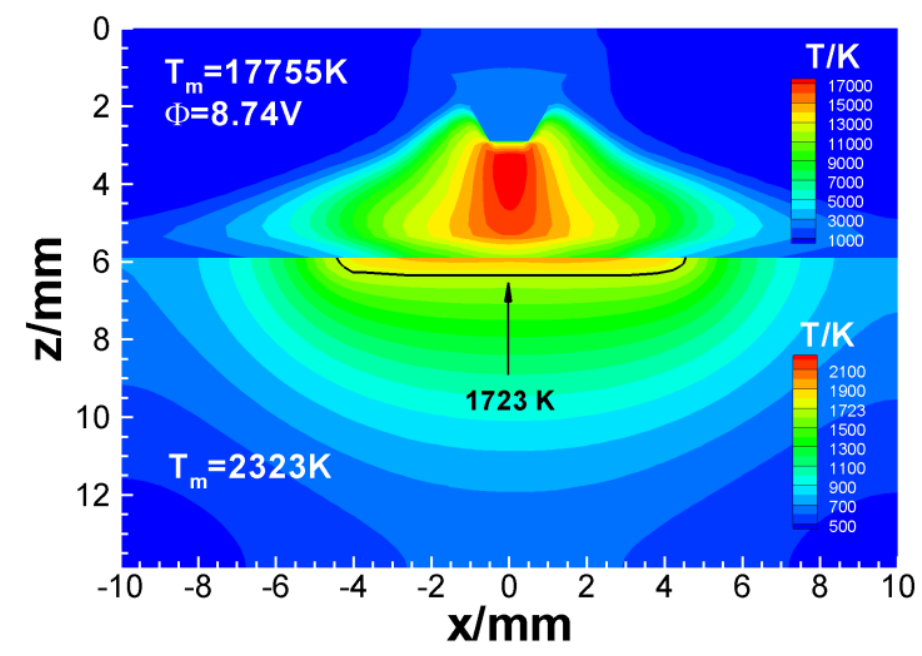

(a)

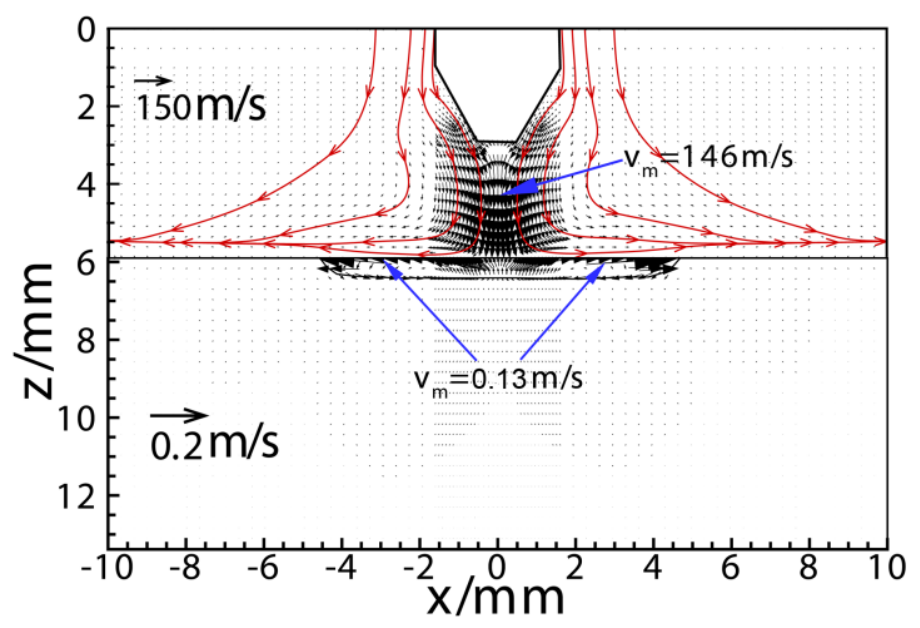

(b)

Figure 2. Temperature and flow fields for $150 \mathrm{~A}$ stationary TIG welding $4 \mathrm{~s}$ after arc ignition,

(a) temperature; (b) velocity 
Figure 3 illustrated the temperature and velocity of arc plasma and weld pool for A-TIG welding. It can be seen in figure 3(a) and (b) that the arc plasma property presents a little difference compare to that of TIG welding in figure 2, only the maxima of temperature, arc voltage and velocity decrease $202 \mathrm{~K}, 0.03 \mathrm{~V}$ and $10 \mathrm{~m} / \mathrm{s}$, respectively. For the weld pool, its profile is plotted by isothermal line of $1723 \mathrm{~K}$, it is shown that the weld depth increases several times and the weld width constricts $2.9 \mathrm{~mm}$ and its geometry becomes narrow and deep compared with that in TIG welding in figure 3(a). The molten metal flow in the weld pool inverses completely and becomes inward, as drawn in figure 3(b). It is this opposite fluid flow in the weld pool that resulted in the great different weld pool shape between the TIG and A-TIG welding. This will be discussed in detail in next section. In addition, although we make the anode temperature varies with time, such increased surface temperature of the weld pool have little influence on the arc plasma. The peak temperature of the weld pool increases to $2720 \mathrm{~K}$, which is about two hundred higher than the results in [25]. This difference can be attributed to the surface tension temperature coefficient $\mathrm{d} / \mathrm{d} T$ used in the model and shorter arc length. In present study, this value is obtained experimentally from weld pool affected by oxygen and is somewhat larger than that in [28], which is for weld pool with high sulphur content, so the inward heat flow in the weld pool becomes stronger. On the other hand, the 3 $\mathrm{mm}$ arc length can results in more intense heat flux than for $5 \mathrm{~mm}$ arc length. The heat flux distribution will be discussed in following section. For the two reasons, the temperature rises accordingly. For the welding process, this greatly increase in weld pool temperature means a different weld thermal cycle, and can lead to a change in microstructure and properties for weld joint. Moreover, the maximum reaches $0.27 \mathrm{~m} / \mathrm{s}$ and almost locates at central point of 
axis of the weld pool due to the inward flow of molten metal develops sufficiently when close to this point. Tanaka [38] predicted a maximum velocity of $0.62 \mathrm{~m} / \mathrm{s}$ at the top surface for TIG welding of SUS 304 stainless steel with high sulphur content. However, as suggested by Zhao et al [39] for weld pool flow of 316L stainless steel with active surface oxide, the weld pool flow at the surface shows strong unsteady with a fluctuation of velocity between $0.15 \sim 0.4 \mathrm{~m} / \mathrm{s}$ time dependently. The more accurate model should be developed in further study.

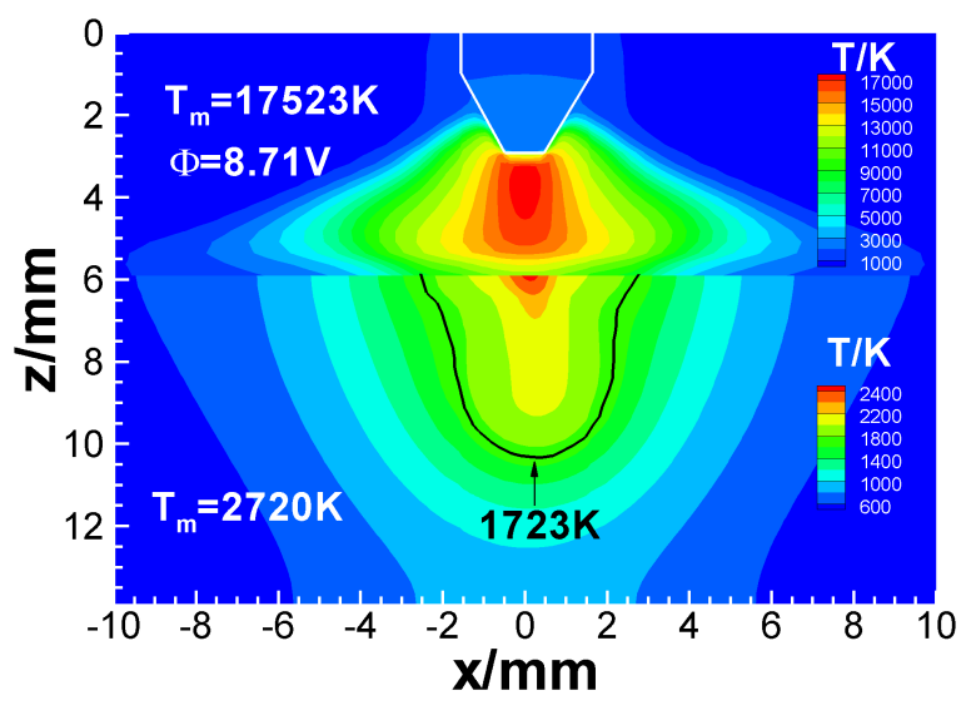

(a)

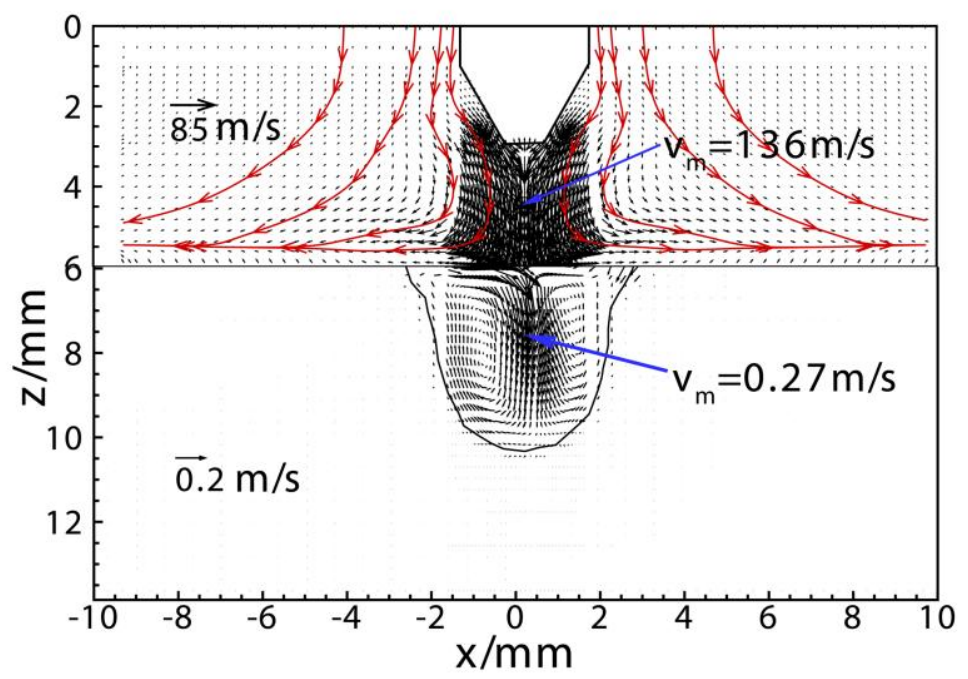

(b) 
Figure 3. Temperature and flow fields for 150 A stationary A-TIG welding $4 \mathrm{~s}$ after arc ignition, (a) temperature; (b) velocity

\subsection{Heat and fluid flow in the weld pool}

\subsubsection{Heat flux and shear stress at the weld pool}

Figure 4 plots the current density component in $z$ direction $j_{z}$ and various heat fluxes at the weld pool surface. As illustrated, all these value decline with the increase in radius and there is no apparent difference in current density and various heat fluxes at the weld pool between TIG and A-TIG welding. Maximum current density approaches to $1 \times 10^{7} \mathrm{~A} \cdot \mathrm{m}^{-2}$, this value is much higher than that calculated for $5 \mathrm{~mm}$ arc length by Tanaka [24] and means more heat intensity. The peak value of total heat flux $q_{\mathrm{a}}$ is $8.51 \times 10^{7} \mathrm{~W} \cdot \mathrm{m}^{-2}$ during TIG welding, and $8.18 \times 10^{7} \mathrm{~W} \cdot \mathrm{m}^{-2}$ during A-TIG welding. These values are close to the experimental data of 8.5 $\times 10^{7} \mathrm{~W} \cdot \mathrm{m}^{-2}$ for $200 \mathrm{~A}$ argon arc with $3.2 \mathrm{~mm}$ arc gap by Nestor [40], and much higher than 5mm arc gap by Tanaka [24]. This increased heat intensity can contributes partly to the elevated weld pool temperature. In addition, the heat flux $q_{\mathrm{e}}$ due to electron absorption at central part of the weld pool surface is dominant, whereas the heat flux $q_{\mathrm{c}}$ due to conduction becomes main heat input at the periphery of the work piece with the increase of radius.

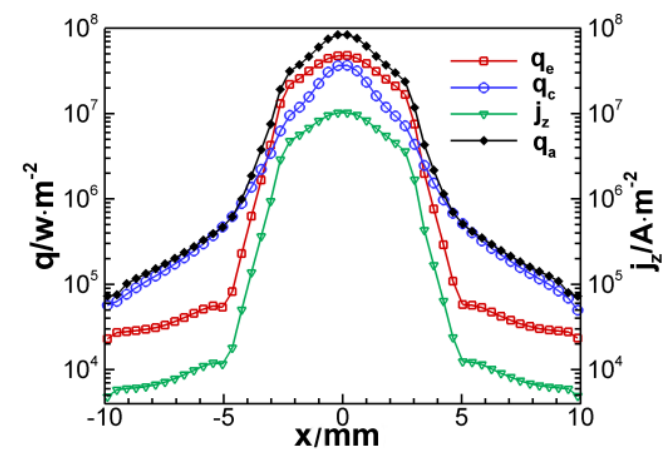

(a)

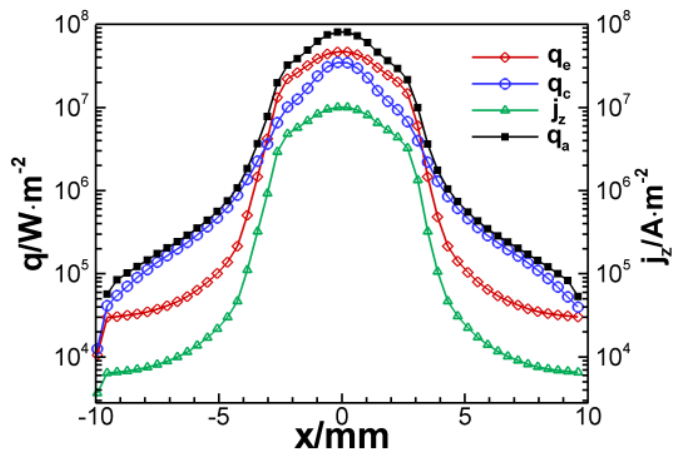

(b)

Figure 4. Current density and heat flux distributions at the weld pool surface for $150 \mathrm{~A}$ stationary welding $4 \mathrm{~s}$ after arc ignition, (a) TIG; (b) A-TIG

In order to get various heat input to the weld pool, we integrate $q_{\mathrm{e}}, q_{\mathrm{c}}$ and $q_{\mathrm{r}}$ over the 
whole anode surface for TIG and A-TIG welding, respectively. Thus,

$$
Q_{\mathrm{a}}=Q_{\mathrm{e}}+Q_{\mathrm{c}}+Q_{\mathrm{r}}=\int_{\Omega} q_{\mathrm{e}} d s+\int_{\Omega} q_{\mathrm{c}} d s+\int_{\Omega} q_{\mathrm{r}} d s=697.5 \mathrm{~W}+450.5 \mathrm{~W}-17 \mathrm{~W}=1131 \mathrm{~W}
$$

for TIG welding, where $Q_{\mathrm{a}}, Q_{\mathrm{e}}, Q_{\mathrm{c}}$ and $Q_{\mathrm{r}}$ are, respectively, heat input due to the electron absorption, heat conduction and radiation loss; $\Omega$ represents integral surface and $s$, integral element. The above equation means the total heat input to the anode $Q_{\mathrm{a}}$ is $1131 \mathrm{~W}$, where $Q_{\mathrm{e}}$ contributes main part of the heat input (61.7\%), and $Q_{\mathrm{c}}$ contributes secondary part (38.3\%). A energy loss of $16.6 \mathrm{~W}$ due to the radiation is very small and can be neglected reasonably. After multiplying calculated arc voltage drop $8.74 \mathrm{~V}$ by welding current $150 \mathrm{~A}$, we can obtain the thermal efficiency for TIG welding is $86.3 \%$ in the case of 150 A current and $3 \mathrm{~mm}$ electrode gap.

Similarly, the heat input to the weld pool surface for A-TIG is

$$
Q_{\mathrm{a}}=Q_{\mathrm{e}}+Q_{\mathrm{c}}+Q_{\mathrm{r}}=\int_{\Omega} q_{\mathrm{e}} d s+\int_{\Omega} q_{\mathrm{c}} d s+\int_{\Omega} q_{\mathrm{r}} d s=697.5 \mathrm{~W}+462 \mathrm{~W}-18.5 \mathrm{~W}=114 \mathrm{WW}
$$

It can be found that the total heat input is $10 \mathrm{~W}$ higher than that of the TIG welding, which is induced by a increase of $11.5 \mathrm{~W}$ of $Q_{\mathrm{c}}$ and a radiation loss of $1.5 \mathrm{~W}$. Considering the computed arc drop $8.71 \mathrm{~V}$, we can acquire the thermal efficiency for the A-TIG welding is 87.3\%. Comparing with TIG welding, the heat input and heat efficiency is almost unchanged. However, the weld penetration and geometry vary significantly due to the conversed convection in weld pool. It should be noted that the calculated thermal efficiency for both the TIG and A-TIG welding are, to some extent, higher than the experimental data [34] and some numerical simulation results[24]. The probable reason is that the exclusion of cathode sheath drop makes the computed voltage drop is lower than the actual value, as discussed in section 4.1.

Figure 5 plotted the shear stress and temperature distributions at the weld pool surface for TIG and A-TIG welding at $4 \mathrm{~s}$. It is shown that Marangoni stress is only generated in liquid zone, so the resultant shear stress distributes in this range, while the effect of plasma drag force is over the whole surface. It can be seen in figure 5(a) that the weld width for TIG 
welding is $8.3 \mathrm{~mm}$, and that for A-TIG welding is $5.4 \mathrm{~mm}$ in figure 5(b). Moreover, the temperature of weld pool surface for A-TIG welding is about $400 \mathrm{~K}$ higher than that for TIG welding. This change is induced by the circulation flow in the weld pool, and discussed in next section.

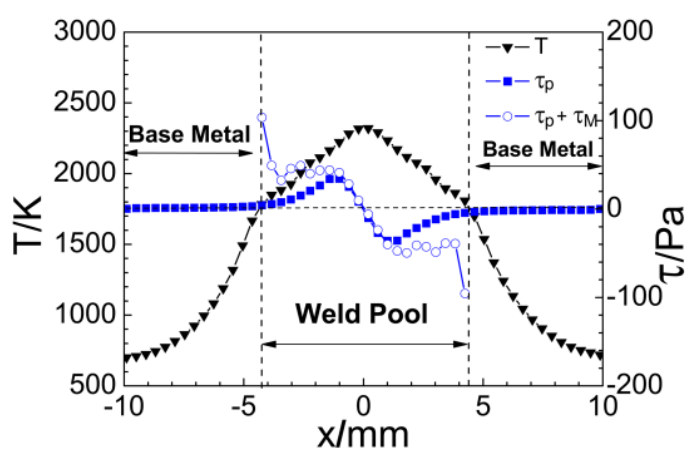

(a)

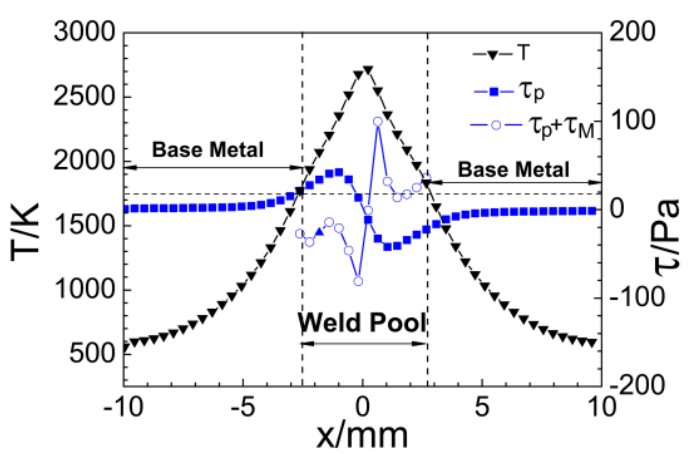

(b)

Figure. 5 Temperature and shear stress distributions at the weld pool surface for $150 \mathrm{~A}$ stationary welding $4 \mathrm{~s}$ after arc ignition, (a) TIG; (b) A-TIG

As regard the shear stress at the weld pool, the plasma drag force $\tau_{\mathrm{p}}$ is almost unchanged and its peak value is over $40 \mathrm{~Pa}$. However, the resultant shear stress consists of $\tau_{\mathrm{p}}$ and Marangoni stress $\tau_{\mathrm{M}}$ is reversed. The maximum resultant stresses reached to140 Pa for TIG welding and $100 \mathrm{~Pa}$ for A-TIG welding. It is noted that the $\tau_{\mathrm{M}}+\tau_{\mathrm{p}}$ increases to a maximum for TIG welding, while the maximum appears close to the central part of the weld pool for A-TIG welding. This is result from the corresponding maximum of temperature gradient occurs at these positions. In next section, the relative importance of various driven force will be discussed. And a fact can be demonstrated: it is this reversed $\tau_{\mathrm{M}}+\tau_{\mathrm{p}}$ that change the molten metal flow in the weld pool from outward for TIG welding to inward for A-TIG welding. 


\subsubsection{Dimensionless analysis for heat and fluid flow}

The effect of various forces on the weld pool are illustrated in figure 6. As shown in figure 6(a), the molten metal in the weld pool flows outwards driven by buoyance. The velocity is in the order of magnitude of $0.01 \mathrm{~m} \cdot \mathrm{s}^{-1}$ and maximum velocity is $0.03 \mathrm{~m} / \mathrm{s}$. The weld pool flow driven by Lorentz force is pictured in figure 6(b), it can be seen that a inward circulation forms in the weld pool and the velocity reaches the magnitude order of $0.1 \mathrm{~m} \cdot \mathrm{s}^{-1}$ with a peak velocity of $0.11 \mathrm{~m} / \mathrm{s}$. For the molten metal flow driven by the plasma drag force and surface tension with negative temperature coefficient, both of them flow outward and the velocities are in the order of magnitude of $0.1 \mathrm{~m} \cdot \mathrm{s}^{-1}$. The maximum velocity driven by plasma drag force is lower than that by surface tension. Moreover, the weld pool extended apparently and becomes shallow, as depicted by solidus line $1673 \mathrm{~K}$. For a positive value of $\mathrm{d} \gamma / \mathrm{d} T$, the intense molten metal flow in the weld pool is from the periphery to the center at the top surface of the weld pool, and then runs towards the weld pool root, which generates a constricted and deep weld pool. That is the effects of the both forces are the same during TIG welding, while the effects become opposite in A-TIG welding.

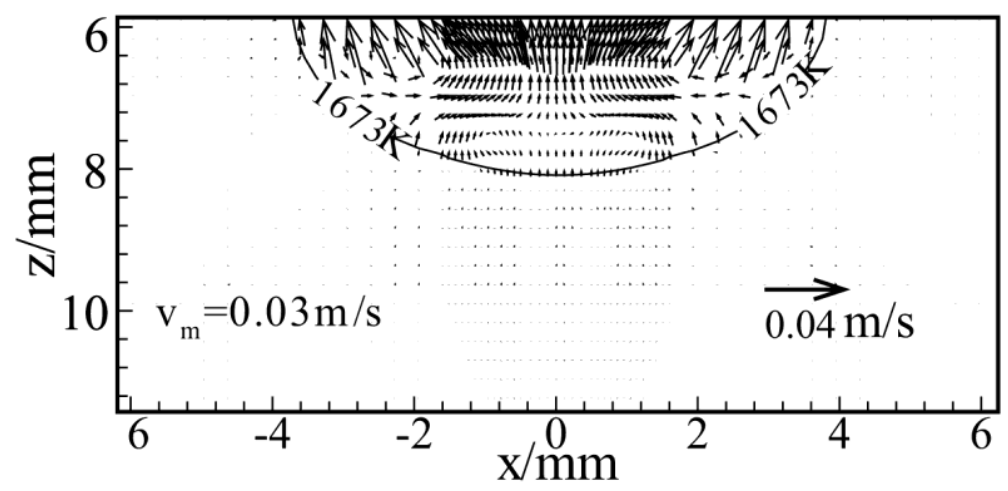

(a) Buoyancy 


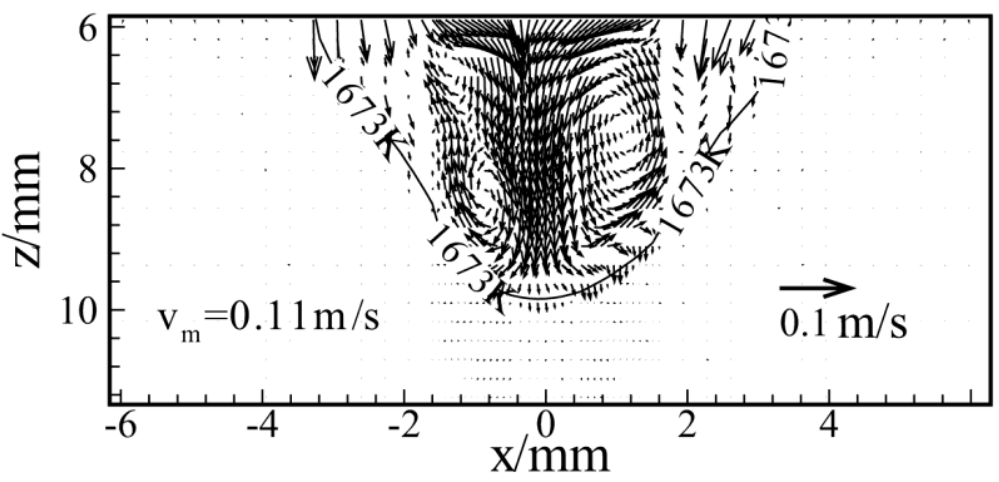

(b) Lorentz force

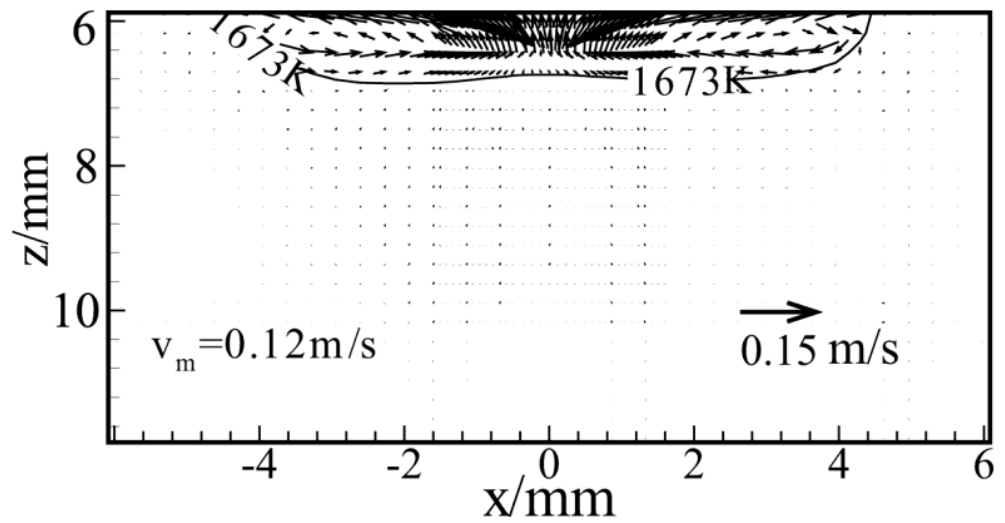

(c) Plasma drag force

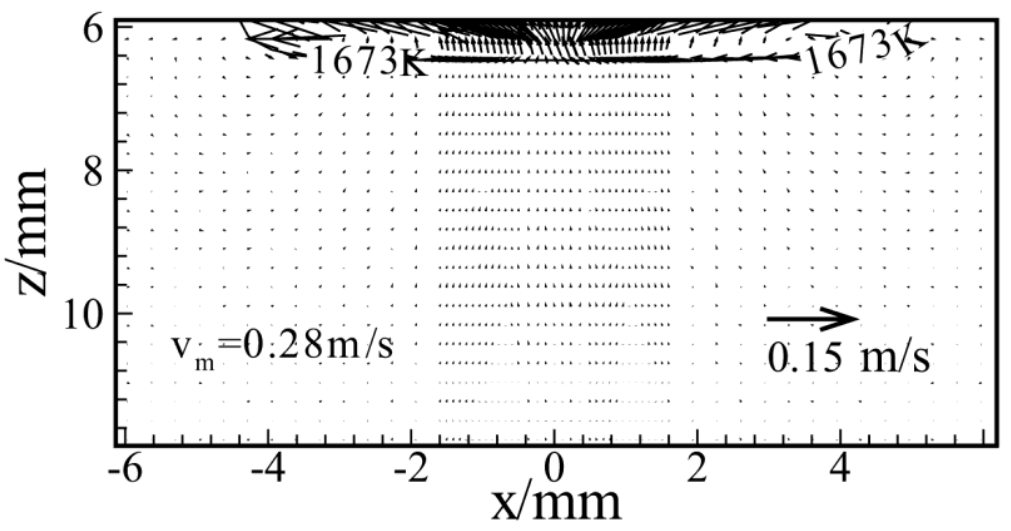

(d) Surface tension, $\mathrm{d} \gamma / \mathrm{d} T<0$ 


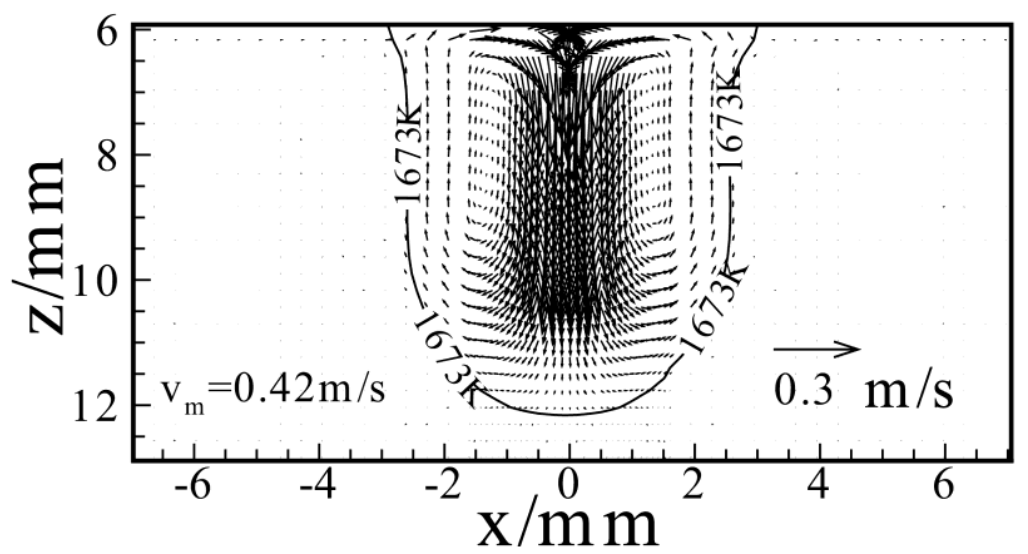

(e) Surface tension, $\mathrm{d} \gamma / \mathrm{d} T>0$

Fig 6 Effect of individual driving force on the weld pool flow, (a) Buoyancy; (b) Lorentz force; (c) Plasma drag force; (d) Surface tension, $\mathrm{d} \gamma / \mathrm{d} T<0$; (e) Surface tension, $\mathrm{d} \gamma / \mathrm{d} T>0$ The relative importance value of buoyancy, Lorentz force and surface tension could be described by using dimensionless numbers [20]. The relative importance of buoyancy and viscous force can be evaluated by Grashof number Gr:

$$
\mathrm{Gr}=\frac{g \beta L_{B}^{3} \Delta T \rho^{2}}{\mu^{2}}
$$

Where $g$ is acceleration of gravity, $\beta$ is coefficient of thermal expansion and $L_{\mathrm{B}}$ is characteristic length of weld pool buoyancy and approximated ordinarily $1 / 8$ of weld pool radius. $\Delta T$ is the difference between the maximum temperature and solid phase temperature of the weld pool, $\rho$ is density of weld pool, and $\mu$, viscosity. For TIG welding, according to the calculated results and the physical properties of SUS 304 stainless steel, $\rho=7000 \mathrm{~kg} \cdot \mathrm{m}^{-3}$, $\beta=10^{-4} \mathrm{~K}^{-1}, L_{\mathrm{B}}=6.25 \times 10^{-4} \mathrm{~m}, \mu=5.5 \times 10^{-3} \mathrm{~kg} \cdot \mathrm{m}^{-1} \mathrm{~s}^{-1}, \Delta T=(2323-1673) \mathrm{K}=650 \mathrm{~K}$. Thus, we obtain $\mathrm{Gr}=252$. For A-TIG welding, $\Delta T=(2720-1673) \mathrm{K}=1047 \mathrm{~K}, L_{\mathrm{B}}=3.4 \times 10^{-4} \mathrm{~m}$, so $\mathrm{Gr}=65$.

Magnetic Reynoldes Number is defined as ratio of electromagnetic force and viscous force, and is formulated as: 


$$
\mathrm{Rm}=\frac{\rho \mu_{m} I^{2}}{4 \pi^{2} \mu^{2}}
$$

Surface Tension Reynoldes Number is calculated by Ma:

$$
\mathrm{Ma}=\frac{\rho L_{R} \Delta T\left|\frac{d \gamma}{d T}\right|}{\mu^{2}}
$$

where $\mu_{m}$ is magnetic permeability of material, $L_{R}$ is characteristic length which is taken as the radius of weld pool upper surface, $d \gamma / d T$ is temperature coefficient of surface tension. It is noted that $\mathrm{Rm}$ is the same for TIG and A-TIG welding, and we could get $\mathrm{Rm}=1.66 \times 10^{5}$. We use these typical values to get $\mathrm{Ma}=2.85 \times 10^{5}$ in TIG welding and $\mathrm{Ma}=3.0 \times 10^{5}$ in A-TIG welding. Thus, the relative importance of these forces could be estimated by the ratio of them. For instance, the importance of Lorentz force of and buoyance is judged by $R_{M / B}$ :

$$
R_{M / B}=\frac{\mathrm{Rm}}{\mathrm{Gr}}
$$

This ratio is 659 for TIG welding and 2554 for A-TIG welding. The relative importance of buoyancy and surface tension could be estimated by the ratio of Ma and Gr,

$$
R_{S / B}=\frac{\mathrm{Ma}}{\mathrm{Gr}}
$$

Thus, the value of $R_{S / B}$ is 1131 during TIG welding, and is 4615 in A-TIG welding.

These dimensionless numbers calculated are listed in Table 2 for clarity. It is indicated that the $R_{S / B}$ is lager than $R_{M / B}$, and Rm and Ma are much larger than Gr for both TIG and A-TIG welding. That means the surface tension is the dominant force driving molten metal flow in the weld pool for both TIG welding and A-TIG welding, the Lorentz force are secondary and the buoyance could be negligible. This order of relative importance is in consistent with the maximum velocity of the weld pool illustrated in figure 6. It can be explained that the stronger driving force is sure to originates stronger flow and as a result, a larger maximum 
velocity. According to this, plasma drag force is considerable due to the peak velocity driven by it reaches $0.12 \mathrm{~m} \cdot \mathrm{s}^{-1}$, which is quite close to that of Lorentz force. Therefore, the relative importance of these driving forces could be surface tension, plasma drag force (Lorentz force) and buoyance.

Table 2 Dimensionless numbers of weld pool flow

\begin{tabular}{lccccc}
\hline Dimensionless & Gr & $\mathrm{Rm}$ & $\mathrm{Ma}$ & $R_{\mathrm{M} / \mathrm{B}}$ & $R_{\mathrm{S} / \mathrm{B}}$ \\
number & & & & & \\
\hline TIG & 252 & $1.66 \times 10^{5}$ & $2.85 \times 10^{5}$ & 659 & 1131 \\
A-TIG & 65 & $1.66 \times 10^{5}$ & $3.0 \times 10^{5}$ & 2554 & 4615 \\
\hline
\end{tabular}

In the weld pool, heat conduction and heat convection are coexisting in heat transfer. In order to distinguish the relative importance of them, dimensionless number Pe, namely Peclet Number, is used [20,41] and it is expressed as

$$
\mathrm{Pe}=\frac{u \rho c_{P} L_{R}}{k}
$$

Where $u$ is typical velocity of the weld pool and is taken as average velocity, $c_{p}$ is specific heat at constant pressure, $L_{\mathrm{R}}$ is characteristic length which is the radius of weld pool upper surface, $k$ and $\rho$ is defined earlier. For TIG welding, we use typical values as $u=0.1 \mathrm{~m} \cdot \mathrm{s}^{-1}$, $7000 \mathrm{~kg} \cdot \mathrm{m}^{-3}, c_{p}=600 \mathrm{~J} \cdot \mathrm{kg}^{-1}, L_{R}=0.0042 \mathrm{~m}$ and $k=20 \mathrm{~W} \cdot \mathrm{m}^{-1} \mathrm{~K}^{-1}$ at $4 \mathrm{~s}$, the Pe equals to 88 . Concerning A-TIG welding, $L_{R}=0.0027 \mathrm{~m}, u$ is relatively larger and we set as $0.15 \mathrm{~m} \cdot \mathrm{s}^{-1}$, so the Pe equals to 85 . This number for both TIG and A-TIG welding is much larger than 1, which means the heat in the weld pool of is transported primarily by convection, and the heat conduction is secondary. In addition, it can be found that Pe is dependent of materials 
properties. This implies that the contribution of the convection and conduction varies for different materials, even if the welding parameters are close, which can generate different weld shape and related thermal processes [42].

The molten metal flow and various heat transfer processes for the weld pool are drawn in figure 7. As indicated in section 4.2.1, the radiation loss can be neglected. During TIG welding process, the molten metal flows from the center to the periphery at the weld pool surface and thus produces a outward flow due to the dominant effect of the Marangoni force, which disperses the most part of the heat input from the arc plasma to the edge of the weld pool and the solidus metal near the weld pool edge is more melted. As a results, a shallow and wide weld pool profile forms. Comparatively, in A-TIG welding process, temperature coefficient of surface tension is altered due to the introduction of the surfactant, and the Marangoni force is reversed. Thus, the molten metal flows from the periphery to the center at the weld pool surface and produces a intense inward flow in the weld pool, which transfers the most heat input from the arc plasma to the central part and then towards the bottom of the weld pool. Therefore, the solidus metal near the weld pool bottom is melted more and the weld width increases remarkably and weld width constricts slightly. Since the total heat input to the weld pool is almost unchanged, as suggested by (11) and (12), it is convinced that the significant modification of weld pool shape is induced directly by inversed heat convection inversed. 


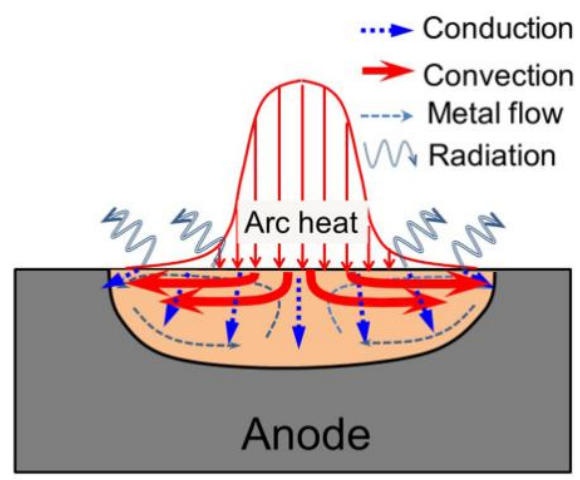

(a)

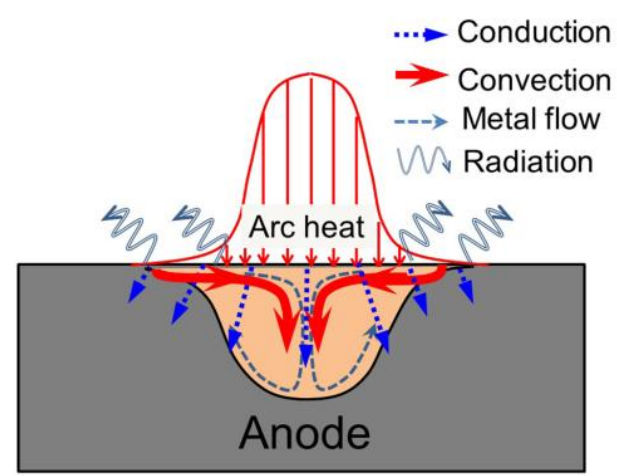

(b)

Figure 7 Schematic diagram of heat transfer and molten metal flow in the weld pool, (a) TIG welding; (b) A-TIG welding

Comparison of calculated and experimental results is illustrated in Fig. 8. The experimental conditions are kept as close as those of calculation. It can be shown that the calculated weld pool shape is in fair agreement with that of experiment. The geometry parameters of weld pool are listed in the table 3 as a comparison. It can be found that the simulated weld shape is much close to the experimental one, while there is a relatively obvious difference between experiments and modeling for A-TIG welding. It can be considered that the one reason of the inconsistence is results from the surface tension variation with the temperature, which is a critical in determining weld pool shape as discussed above. In fact, the temperature coefficient of surface tension is a function of temperature and surfactants content. The weld pool flow can be affected by the distributions of both the activating element and temperature at the weld pool $[39,43]$. This is an issue of significance to be given more focus sequentially. On the other hand, the simplification of anode-arc interface may cause the deviation and a more accurate anode model should be developed.

Table 3 Comparison of weld pool dimensions 


\begin{tabular}{ccccc}
\hline & \multicolumn{3}{c}{ Weld width W/mm } & \multicolumn{2}{c}{ Weld depth $D / \mathrm{mm}$} \\
\cline { 2 - 5 } & Experimental & Calculated & Experimental & Calculated \\
TIG & 9.2 & 8.3 & 0.85 & 0.65 \\
A-TIG & 8.4 & 5.4 & 3.9 & 4.4 \\
\hline
\end{tabular}

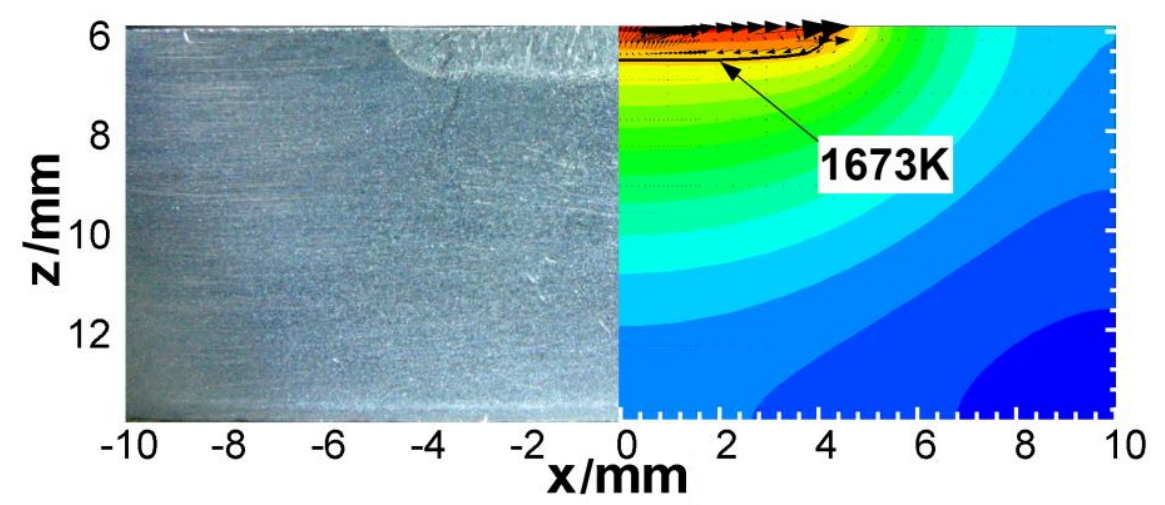

(a)

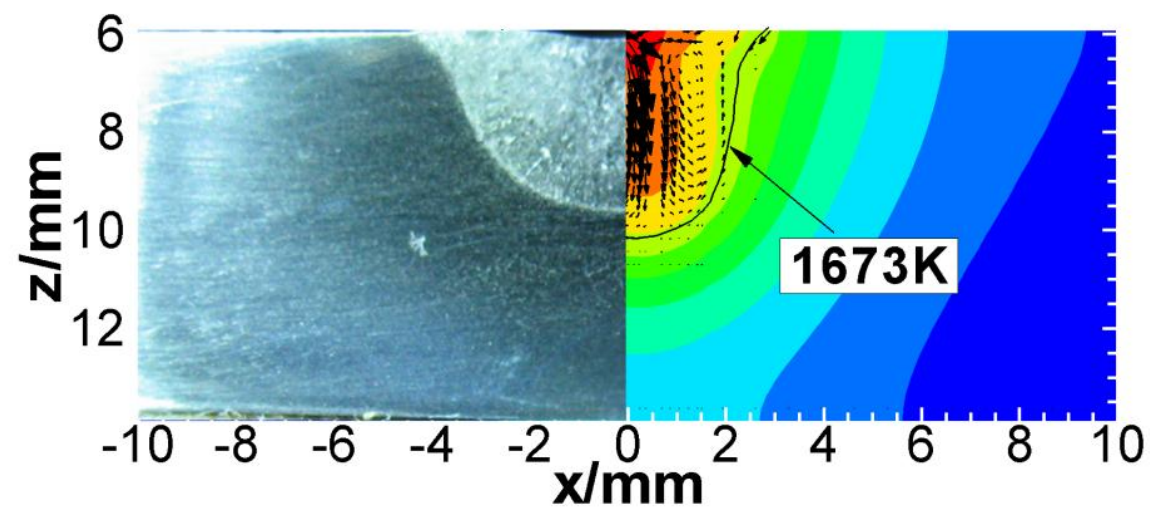

(b)

Fig 8 Comparison of calculated and experimental results of weld pool morphology, (a) TIG welding; (b) A-TIG welding

\section{Conclusions}

The heat transfer and fluid flow in TIG and A-TIG welding of stainless steel SUS304 are 
investigated based on a 3D unified model; the conclusions obtained can be summarized as follows:

(1) Temperature coefficient of surface tension inversion from negative to positive results in conversed weld pool flow, and thus a sharply increased weld penetration in A-TIG welding.

(2) Molten metal flow in the weld pool is dominated by Marangoni force, and convection is the primary mechanism of the heat transfer in weld pool. It is the combination of the two effects that results shallow and wide weld pool shape in TIG welding and constricted and deep weld pool shape in A-TIG welding.

(3) In more realistic welding condition, the current density and the heat flux at the weld pool are more concentrated and thus both of the temperature of the weld pool for TIG welding and A-TIG welding increases, while the latter is more significant.

(4) Increased temperature and inward flow of the weld pool have little effect on the arc plasma, and heat input to the work piece is almost kept a constant for both TIG and A-TIG welding.

\section{Acknowledgments}

This work is supported by National Science Foundations of China (NSFC) [grant numbers 51074084, 51205179], and Scientific and Technological Research Program of Chongqing Municipal Education Commission [grant number KJ1600903].

\section{References}

[1] Gurevich S M, Zamkov V N, Kushnirenko N A. Increase in the efficiency of penetration of titanium alloys in argon arc welding. Avtomatich Svarka, 1965, 9: 1-5 
[2] Howse D S, Lucas W. Investigation into arc constriction by active flux for tungsten inert gas welding. Science and technology of welding and joining, 2000, 5(3): 189-193

[3] Leconte S, Paillard P, Chapelle P, Henrion G, Saindrenan J. Effects of flux containing fluorides on TIG welding process. Science and technology of welding and joining, 2007, 12(2): $120-126$

[4] Prilutsky V P, S V Akhonin. TIG welding of titanium alloys using fluxes. Welding in the World, 2014, 58(2): 245-251

[5] Marya M. Theoretical and experimental assessment of chloride effects in the A-TIG welding of magnesium. Welding in the World, 2002, 46, (7/8): 7-21

[6] Pollard B. The effects of minor elements on the welding characteristics of stainless steel. Welding Journal, 1988, 67(9): S202-S213

[7] Heiple C R, Roper J R. Effect of selenium on GTAW fusion zone geometry. Welding Journal, 1981, 60(8): S143s-S145

[8] Heiple C R, Roper J R, Stagner R T, Aden R J. Surface active element effects on the shape of GTA, laser and electron beam welds. Welding Journal, 1983, 62(3): S72-S77

[9] Aidun D K, Martin S A. Effect of Sulfur and oxygen on weld penetration of high-purity austenitic stainless steels. Journal of Materials Engineering and Performance, 1997, 6(4): 496-503

[10] Lu S P, Fujii H, Nogi K. Weld shape comparison with iron oxide flux and $\mathrm{Ar}-\mathrm{O}_{2}$ shielding gas in gas tungsten arc welding. Science and Technology of Welding and Joining, 2004, 9(3): 272-276

[11] Fan D, Lin T, Huang, Y. Arc assisted activating TIG welding. Transactions of the China 
Welding Institution, 2008, 29(12): 1-6

[12] Zhang R H, Pan J L, Katayama S. The mechanism of penetration increase in A-TIG welding, Frontiers of Materials Science in China, 2011, 5(2): 109-118

[13] Ogawa Y. High speed imaging technique Part 1-high speed imaging of arc welding phenomena. Science and Technology of Welding and Joining, 2011, 16(1): 33-43

[14] Zhang R H, Fan D. Numerical simulation of effects of activating flux on flow patterns and weld penetration in ATIG welding. Science and Technology of Welding and Joining, 2007, 15(1): $15-23$

[15] Hsu K C, Etemadi K, Pfender E. Study of the free burning high intensity argon arc. Journal of Applied Physics, 1983, 54(3), 1293-1301

[16] McKelliget J, Szekely J. Heat transfer and fluid flow in the welding arc. Metallurgical and Materials Transactions A, 1986, 17 (7): 1139-1148

[17] Tsai M C, Kou S. Heat transfer and fluid flow in welding arcs produced by sharpened and flat electrodes. International Journal of Heat and Mass transfer, 1990, 33(10): 2089-2098 [18] Oreper G M, Szekeley J. Heat-and fluid-flow phenomena in weld pools. Journal of Fluid Mechanics, 1984, 147(10): 53-79

[19] Wang Y, Shi Q, Tsai H L. Modeling of the effects of surface-active elements on flow patterns and weld penetration. Metallurgical and Materials Transactions B, 2001, 32(1): $145-161$

[20] Zhang W, Roy G G, Elmer J W, DebRoy T. Modeling of heat transfer and fluid flow during gas tungsten arc spot welding of low carbon steel. Journal of Applied Physics, 2003, 93(5): 3022-3034 
[21] Choo R T C, Szekely J, Weswthoff R C. On the calculation of the free surface temperature of gas-tungsten-arc weld pools from first principles: Part I. Modeling the welding arc. Metallurgical and Materials Transactions B, 1992, 23(3): 357-369

[22] Choo R T C, Szekely J, David S A. On the calculation of the free surface temperature of gas-tungsten-arc weld pools from first principles: Part II Modeling the weld pool and comparison with experiments. Metallurgical and Materials Transaction B. 1992(23B): $371-384$

[23] Dong W, Lu S, Li D, Li Y. GTAW liquid pool convections and the weld shape variations under helium gas shielding. International Journal of Heat and Mass Transfer, 2011, 54 (7-8): $1420-1431$

[24] Tanaka M, Terasaki H, Ushio M, Lowke J J. A unified numerical modeling of stationary tungsten-inert-gas welding process. Metallurgical and Materials Transactions A, 2002, 33(7): $2043-2052$

[25] Tanaka M. Effects of surface active elements on weld pool formation using TIG arcs. Welding International, 2005, 19 (11): 870-876

[26] Lowke J J, Tanaka M, Ushio M. Mechanisms giving increased weld depth due to a flux. Journal of Physics D: Applied Physics, 2005, 38 (18): 3438-3445

[27] Mougenot J, Gonzalez J J, Freton P, Masquère M. Plasma-weld pool interaction in tungsten inert-gas configuration. Journal of Physics D: Applied Physics, 2013, 46(13): $135206-135220$

[28] Tanaka M, Yamamoto K, Tashiro S, Nakata K, Yamamoto E, Yamazaki K, Suzuki K, Murphy A B, Lowke J J. Time-dependent calculations of molten pool formation and thermal 
plasma with metal vapour in gas tungsten arc welding. Journal of Physics D: Applied Physics, 2010, 43(43): 434009-434019

[29] Wang X, Fan D, Huang J, Huang Y. A unified model of coupled arc plasma and weld pool for double electrodes TIG welding. Journal of Physics D: Applied Physics, 2014, 47(27): $275202(14 p p)$

[30] Fan D, Huang Z, Huang J, Wang X, Huang Y. Three-dimensional numerical analysis of interaction between arc and pool by considering the behavior of the metal vapor in tungsten inert gas welding. Acta Physica Sinica, 2015, 64(10): 108102 (10pp)

[31] Voller V R, Prakash C. A fixed grid numerical modelling methodology for convection-diffusion mushy region phase-change problems. International Journal of Heat and Mass Transfer, 1987, 30(8): 1709-1719

[32] Matsuda F, Ushio M, Kumagai T. Study on gas-tungsten-arc electrode (Report 1) comparative study of characteristics of oxide-tungsten cathode. Transactions of JWRI, 1986, 5(1):13-19.

[33] Lowke J J, Tanaka M. LTE-diffusion approximation for arc calculations. Journal of Physics D: Applied Physics, 2006, 39(16): 3634-3643.

[34] Wu C S. Welding Thermal Process and Molten Pool Dynamic. 2008. (Beijing: Mechanical Industry Press), p 123

[34] Giedt, W H, Tallerico LN, Fuerschbach P W. GTA Welding efficiency: calorimetric and Temperature field measurements. Welding Journal, 1989, 68(1): 28s-32s

[35] Bachmann B, Kozakov R, Gött G, Ekkert K, Bachmann J P, Marques J L, Schöpp H, Uhrlandt D, Schein J. High-speed three-dimensional plasma temperature determination of 
axially symmetric free-burning arcs. Journal of Physics D: Applied Physics, 2013, 46(12):125203 (16pp)

[36] Haddad G N, Farmer A J D. Temperature measurements in gas tungsten arcs. Welding Journal, 1985, 64(12): S339-S342

[37] Stuart C Snyder and Robin E Bentley. A measurement of axial velocity and temperature in a free-burning arc using Thomson scattering. Journal of Physics D: Applied Physics, 1996, 29(12): 3045-3049

[38] Tanaka. Effects of surface active elements on weld pool formation using TIG arcs. Welding International, 2005, 19(11): 870-876

[39] Zhao C X, Steijn V, Richardson I M, Kleijn C R, Kenjeres S, Saldi Z. Unsteady interfacial phenomena during inward weld pool flow with an active surface. Science and Technology of Welding and Joining, 2009, 14 (2): 132-140

[40] Nestor O H. Heat intensity and current density distributions at the anode of high current, inert gas arcs. Journal of Applied Physics, 1962, 33 (5): 1638-1648

[41] Kumar A, DebRoy T. Calculation of three dimensional electromagnetic force during arc welding. Journal of Applied Physics, 2003, 94(2): 1267-1279

[42] Rai R, Elmer J W, Palmer T A, DebRoy T. Heat transfer and fluid flow during keyhole mode laser welding of tantalum, Ti-6Al-4V, 304L stainless steel and vanadium. Journal of Physics D: Applied Physics, 2007, 40 (18): 5753-5766

[43] Winkler C, Amberg G, Inoue H, Kosekib T, Fujia M. Effect of surfactant redistribution on weld pool shape during gas tungsten arc welding. Science and Technology of welding and Joining, 2000, 5(1): 8-21 